\title{
Design and Development of Circular Polarized Conformal Microstrip patch Antenna
}

\author{
CH V Ravi Sankar, D. Swetha, P V Y Jayasree
}

\begin{abstract}
This paper presents broadband circular polarized conformal antenna with a square patch for on-board applications. The substrate is located in between patch and the ground. A novel Circular polarized square patch with microstrip feed with two truncated corners with conformal structure is designed. Using a parametric study on the effect of the position of feed, the antenna parameters VSWR bandwidth, half power beam width and polarization of antenna are analysed. Finally fabrication of conformal square patch on 2.2 dialectic substrate and measured results are discussed.

Keywords : conformal microstrip antenna, circular polarization, truncated square corners, VSWR
\end{abstract}

\section{INTRODUCTION}

Microstrip antennas with low dielectric constant circuit board substrate have the advantages of broad band, high gain and reproducibility [1]. Now a day's communication and navigation systems need small and conformal antennas [2]. Circular polarization having some advantages over linear polarization.

There are more than fifteen different antennas causing aerodynamic drag and increased fuel consumption [3]. Integrating these models into the aircraft or curved structures is more difficult. The conformal antenna is popular for aircraft, UAV, ships, and satellite. These structures have shapes like cylindrical and conical types [4].

The proposed design is circularly polarized conformal structure. First, the design of conformal MSP antenna and truncated corners for patch to achieve Circular polarization is presented in Section two. After, the simulated and measured results of antenna are shown in Section three. Comparison of fabricated results of the circular polarized conformal antenna with simulated results is also discussed.

\section{CONFORMAL ANTENNA DESIGN}

The simulated antenna with trial and error method, achieved a square patch for our requirements. For getting circular polarization two feeds are used on both sides of patch but it is very difficult to achieve [5]. The alternative method is cutting corners of patch with equal length generates orthogonal modes. The simulated geometry of conformalantenna is illustrated in Figure 1. The antenna is

Revised Manuscript Received on December 13, 2019.

* Correspondence Author

CH V Ravi Sankar Dept. of Electronics and Communication Engineering, Aims college of Engineering,Mummidivaram, Zip Code:533216, Email: ravisankar452@gmail.com

D Swetha, Dept. of Electronics and Communication Engineering, Malineni perumallu educational societies,Guntur, Zip Code:522017, Email:

Dr.P V Y Jayasree, , Dept. of Electronics and Communication Engineering, GITAM University Vizag, Zip Code:530045, Email: pvyjayasree@gitam.edu swethatragadda88@gmail.com

simulated in 3D electromagnetic simulator software which is HFSS software that uses finite element method. The simulation results present EM solutions like s-parameters and field calculations

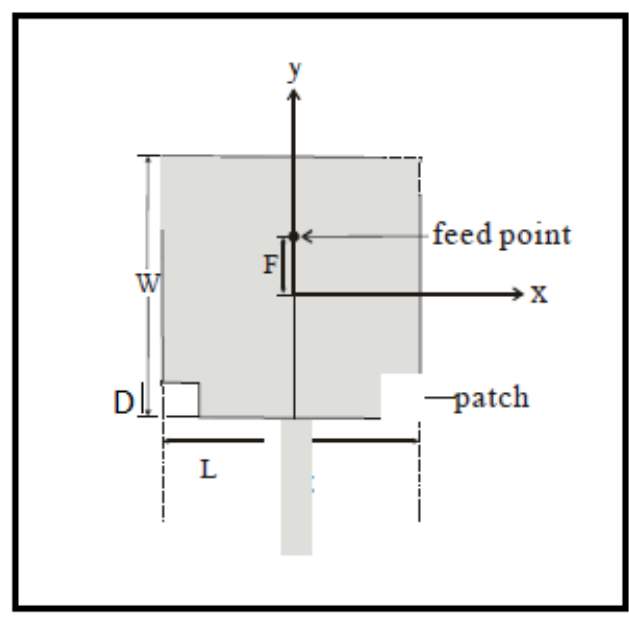

Fig. 1 Geometry of the circular polarized MSP antenna

To get circular polarization, the truncated corners designed using following equations

$$
\begin{aligned}
& \Delta s / S=1 / 2 q \\
& f_{1}=f_{0}[1-(2 \Delta s) / S] \quad------ \text { eq2 }
\end{aligned}
$$

$\Delta s$ - perturbation area,

$S$ - of patch,

$\mathrm{Q}$-.quality factor

The patch radius can be determined using a theoretical model with dielectric constant and frequency, thickness of substrate.

The equation for Radius of patch as:

$$
\begin{aligned}
& a=\frac{F}{\left\{1+\frac{\mathrm{nh}}{\pi \in r F[}\left[\ln \left(\frac{\pi F}{\operatorname{sh}}\right)+1.7726\right]\right] 1 / 2} \ldots . \text { eq3 } \\
& F=\frac{g .791 \times 10^{\circ}}{f r \sqrt{E Y}} \quad \text {..............eq4 }
\end{aligned}
$$

Conformability can be defined as a map projection which has the property of preserving relative angles over small scales. 


\section{Design and Development of Circular Polarized Conformal Microstrip patch Antenna}

In Mathematics, a conformal map is a function which preserves angles. A vision of a future conformal antenna consists of all electronic components which is useful for communication in single design.

\section{RESULTS: COMPARISON AND ANALYSIS}

The simulated conformal MSP antenna is shown in Figure 2. Conformal antenna with using 2.2 dielectric constant with dimensions of square patch with $19 \mathrm{~mm} \times 19.6 \mathrm{~mm}$. Figure 3 shows simulated graphical view of antenna.

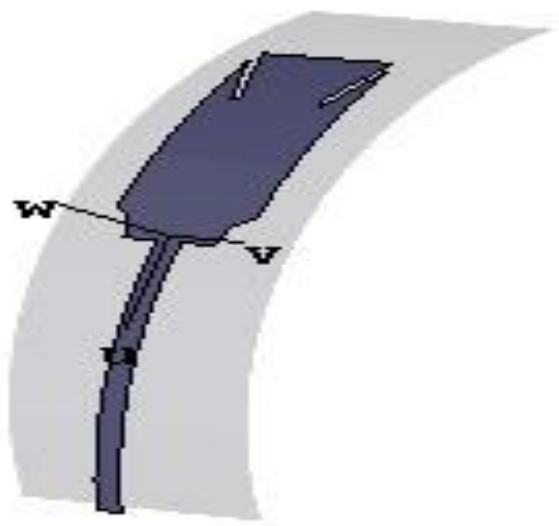

Fig.2. conformal Antenna Geometry in HFSS

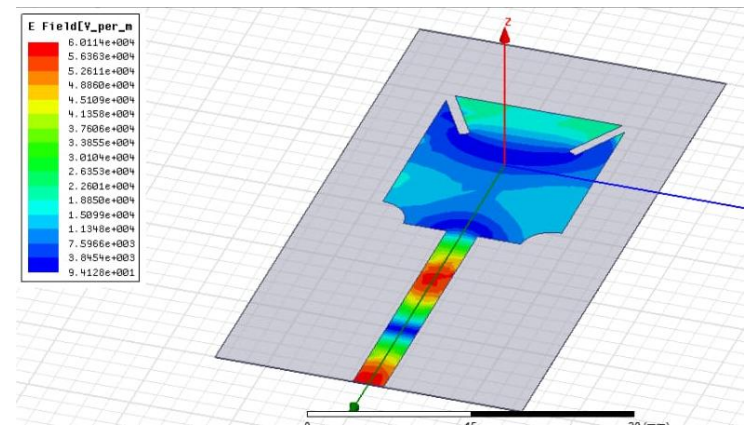

Fig.3. Graphical View of antenna

The simulated VSWR of conformal antenna shows in Figure 4 , it observed good value of VSWR less than 2. The bandwidth is $480 \mathrm{MHz}$ for frequency band. Figure.5 represents the 3-D radiation characteristics of conformal microstrip antenna Figure5 shows simulated radiation pattern for conformal MSP antenna.

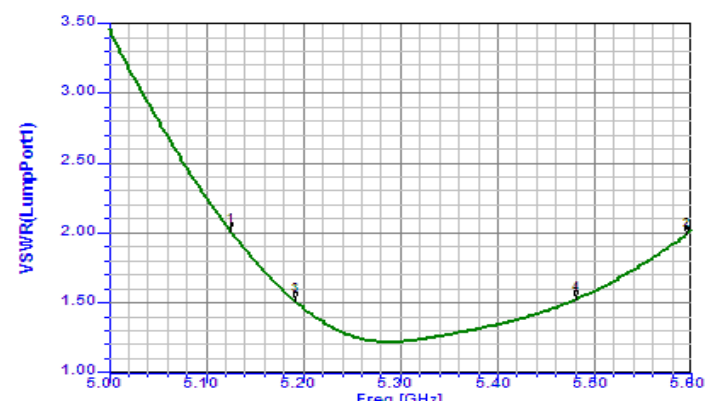

Fig 4. Simulated VSWR vs Frequency

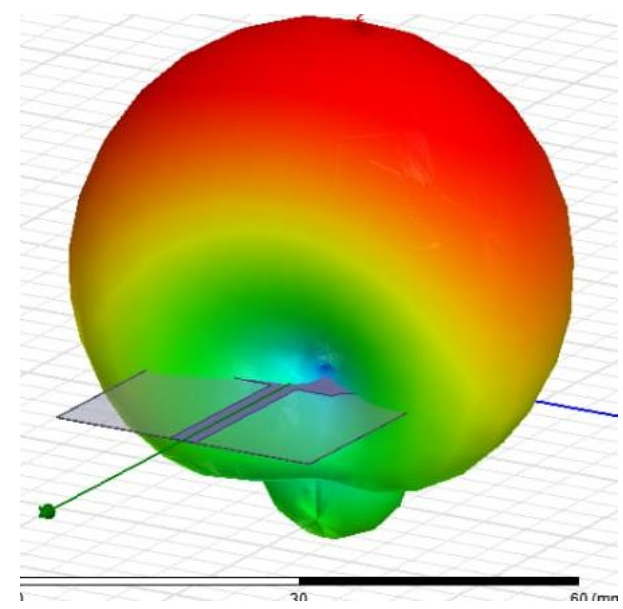

Fig 5. 3-D model pattern for conformal MSP Antenna Figure6. Shows simulated radiation pattern of conformal MSP antenna. The $3 \mathrm{db}$ beam width is $53^{\circ}$ and $125^{\circ}$ azimuth and elevation planes for conformal MSP antenna.

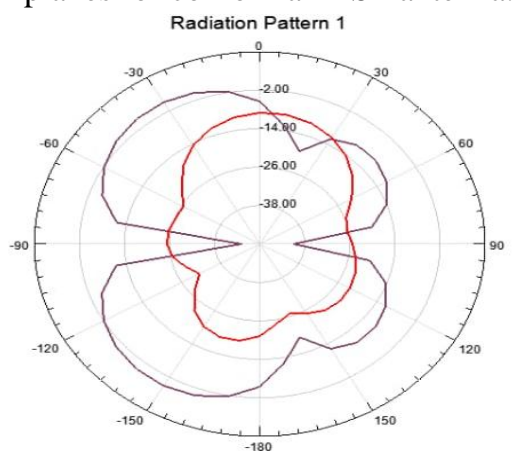

Fig.6. simulated Radiation pattern

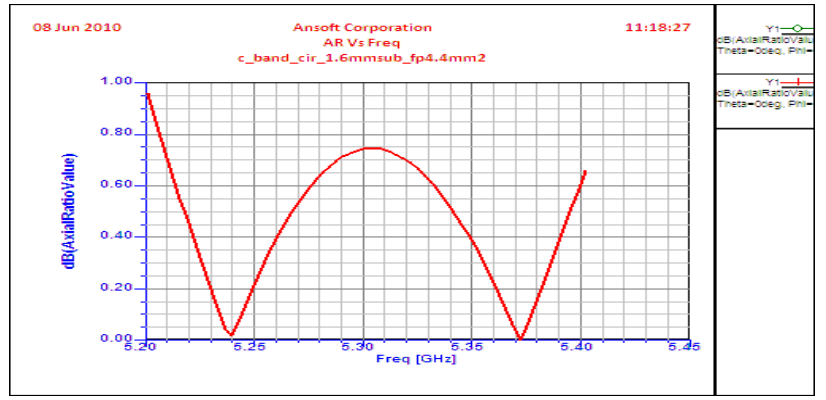

Fig 7. Simulated Axial Ratio

Figure7. Shows axial ratio vs Frequency plot for conformal MSP antennas.it shows almost one, for circular polarization AR is 1 .

By using simulated antenna specifications with trial and error method the antenna is fabricated with 2.2 dielectric constant with $1.6 \mathrm{~mm}$ thickness. The fabricated conformal MSP antenna for circular polarization is shown in Figure 8. The proposed conformal antenna was evaluated for its performance. Figure 9 to12 shows measured VSWR and Radiation pattern, and Gains respectively for conformal MSP antenna. 


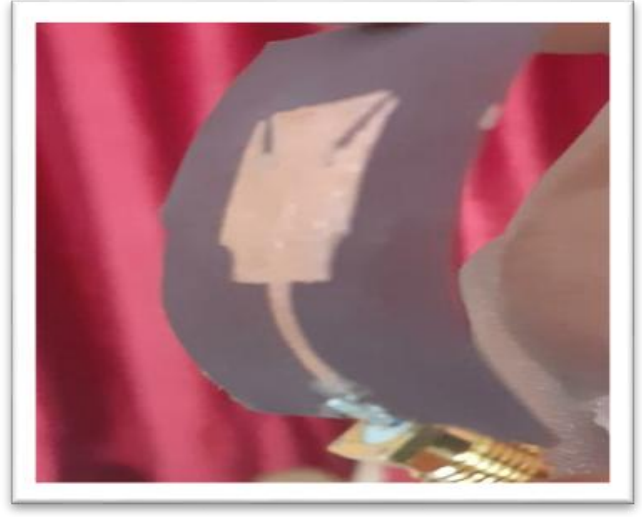

Fig 8.Radiation pattern for conformal Antenna

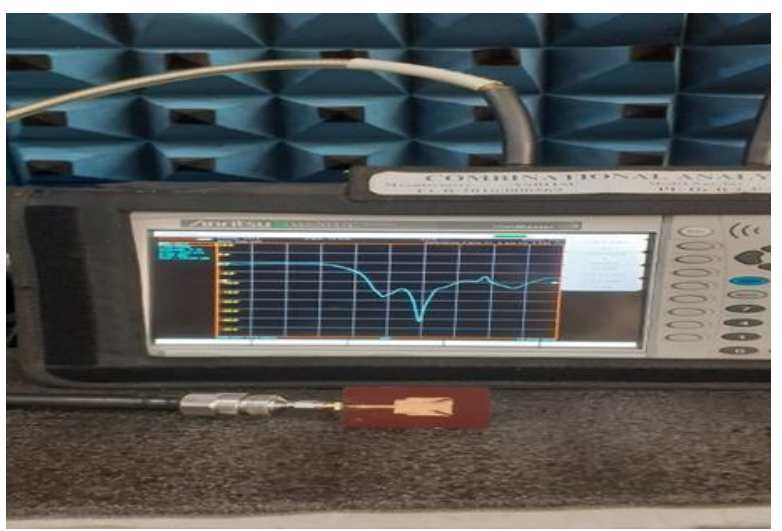

Fig .9 Measured Return loss for Fabricated Antenna Using Network analyzer

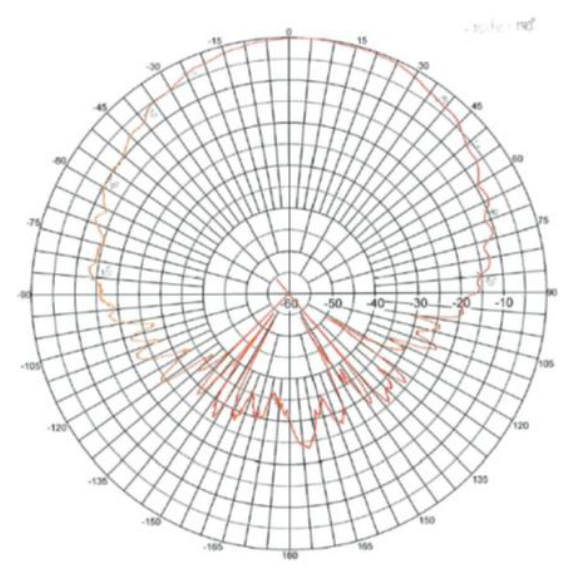

Fig.10. Radiation patterns in azimuth plans for conformal antenna

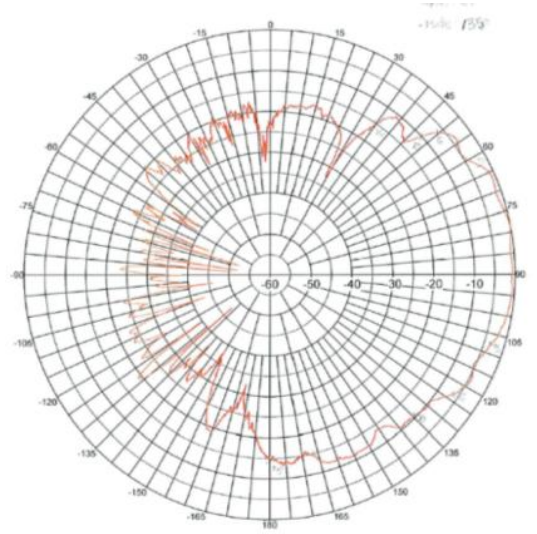

Fig.11. Radiation patterns in azimuth and elevation plans for conformal antenna

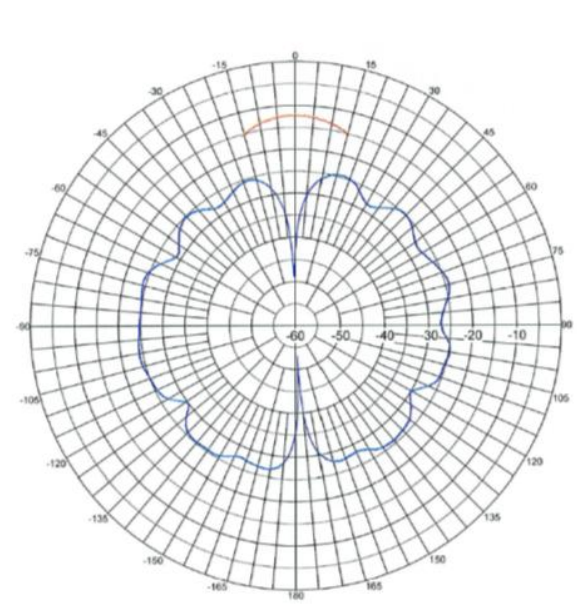

Fig.12. Measured Gain For conformal MSP antenna

\section{CONCLUSION}

A conformal microstrip patch with circular polarization applications has been designed and developed. The measured results valid with the simulated results. The effect of truncating edges of patch antenna is studied. The measured VSWR bandwidth is $400 \mathrm{MHz}$ for a VSWR $<2$ and an axial ratio $<3 \mathrm{~dB}$ and gain of the antenna is $7 \mathrm{~dB}$. The half power beam width is 57 degrees and 130 degrees in both azimuth and elevation planes the conformal MSP antenna.

\section{REFERENCES}

1. S. Raffaelli, Z. Sipus and P.-S. Kildal, "Analysis and Measurements of Conformal Patch Array Antennas on Multilayer circular Cylinder", IEEE Trans. on Antennas and Propagation, Vol. 53, No. 3, Marc

2. Satpathy, S., K. P. Ray, and G. Kumar, "Compact Microstrip Antennas Using a Single Shorting Post,'” Proc. NSAML, New Delhi, India, March 1998, pp. 69-72.

3. Hirasawa, K., and M. Haneishi, Analysis, Design, and Measurement of Small and Low- Profile Antennas, Norwood, MA: Artech House, 1992.

4. James, J. R., and P. S. Hall, Handbook of Microstrip Antennas, Vol. 1, and London: Peter Peregrinus, Ltd., 1989.

5. Naftali Herscovici, Z. Sipus and P.-S. Kildal, "The Cylindrical Omnidirectional Patch Antenna", IEEE Trans. on Antennas and Prop., Vol. 49, No. 12, Dec 2001

\section{AUTHORS PROFILE}

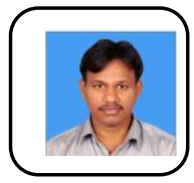

CH V Ravisankar received his B.Tech degree in Electronics \& Communication Engineering from BVC Institute Of Technology \& sciences, affiliated to JNTUK Kakinada. M.Tech in RF\& Microwave Engineering in GITAM Inistitute of Technology, GITAM Deemed to be University, Visakhapatnam. His reresearch area interests Antenna and Microwaves. 


\section{Design and Development of Circular Polarized Conformal Microstrip patch Antenna}

Dr.PVYJayasree received her B.E degree in Electronics \&Communication Engineering from College of Engineering, GITAM affiliated to Andhra University in 1989.M.E in Electronics \& Communication Engineering from Andhra University, Visakhapatnam in 1999.Ph.D in Electromagnetic interference and Compatibility from JNTUK, Kakinada in 2010.Presentlyworking as Professor \& HOD, Department of Electronics \&CommunicationEngineering,GITAMUniversity,Visakhapatna m,Andhrapradesh,India. Her research Interests are Electromagnetic interference and Compatibility, Antennas and Microwaves.

K.Swetha received her B.Tech in Electronics \&Communication Engineering from Vignan's Institute of information Technology in 2009, M.tech in VLSI from JNTUH, Hyderabad. Her research interests are $5 \mathrm{G}$ antennas. 